\title{
VIRTUAL MUSEUMS - THE FUTURE OF HISTORICAL MONUMENTS DOCUMENTATION AND VISUALIZATION
}

\author{
K. Pavelka, jr. ${ }^{1}$, P. Raeva ${ }^{1}$ \\ ${ }^{1}$ Czech Technical University in Prague, Faculty of Civil Engineering, Dept. of Geomatics, \\ Thákurova 7, Prague 6, 166 29, karel.pavelka@hotmail.com, paulina.raeva@fsv.cvut.cz
}

\author{
Commission II, WG II/8
}

KEY WORDS: Virtual reality, virtual museum, photogrammetry, IBMR, documentation, heritage, monuments

\begin{abstract}
:
Technology development now allows us to display the virtual reality (VR) world in a relatively high quality. VR is beginning to be used in many fields and getting many uses. This technology will be used more and more in the future and photogrammetry will not be an exception. For a long time, it has not been possible to present models in any other interesting form than in simple 3D model viewers or directly in the software where this model was built. In our case, this technology was used to create a beta version of a virtual museum that includes, in the beginning, some historical objects documented last year with appropriate technology which allows the transfer of models directly to the VR world. All the models that were presented in the museum had been created from aerial or ground photos, and some of them had been created by a combination of both technologies or in combination with laser scanned data. If we want to use 3D models from photogrammetry, which gets us a realistic copy of a documented object, it is necessary to optimize the photogrammetrical technology for the VR use. The paper introduces all steps of the workflow of how we can obtain a model which could be applicate in VR.
\end{abstract}

\section{INTRODUCTION}

\subsection{Introduction}

At the Czech Technical University, Faculty of Civil Engineering, Dept. of Geomatics, there is a Laboratory of Photogrammetry, which has long been (since the 1960s) focused on the documentation of historical monuments (Sedina, 2017). During more than fifty years, the technology of documentation and the used instruments have changed dramatically, from analogue cameras and analogue data processing to digital recording and processing based on computer technology. Now, typical products are digital orthophotos, 3D models and vector plans in digital form (Sedina, 2015). During the last decade, a new technology of created 3D models visualization was introduced - from static 3D models to moving models with a possibility to analyze these models based on virtual computer models. This brought about the technology of virtual reality (VR) and augmented reality (AR).

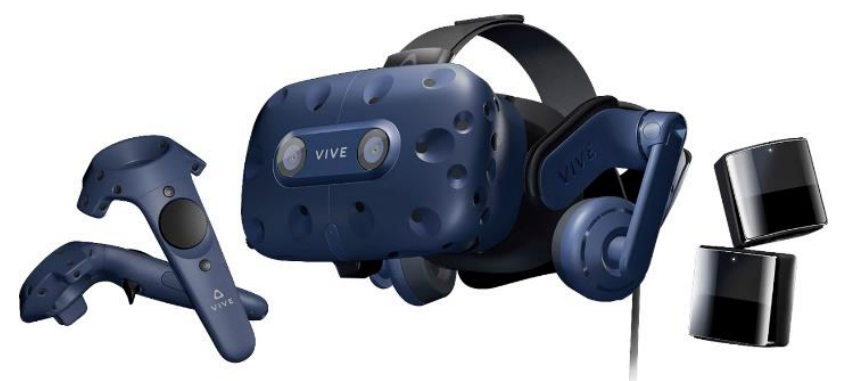

Figure 1. HTC Vive Pro with controllers and lighthouses

At this time, our VR museum contains about 10 historical models from all over the world, but we are also working on other models from our rich stock supply of already solved projects.

\section{WORKFLOW}

\subsection{Data collection and processing}

The workflow starts by capturing data on the site to be documented. In this case, the so called IBMR (Image Based Modeling and Rendering) technology, which uses image correlation on overlapped photographs, was used to create all of the models for the VR museum, so the data were only captured by a good but, nowadays, common camera like digital single-lens reflex (DSLR) cameras.

For good results, it was necessary to get high-quality photos around or over the documented object with a wide overlap between them. Figure 2 shows the positions of photographs displayed as blue rectangles. 


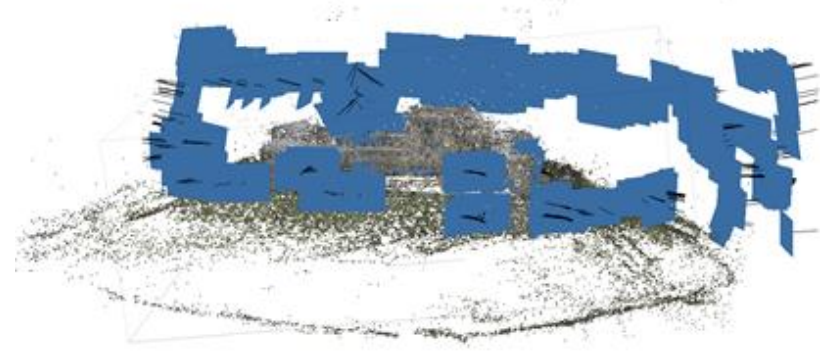

Figure 2. Castle in Stafford

The captured data are processed in the software which uses automatic image correlation to create a 3D model (IBMR technology). In our case, the Agisoft software was used as very popular software for creating 3D rendered models from photographs. At the beginning of the process, the software creates a spare point cloud. In this step, the program detects well visible and important (key) points and calculates the elements of internal and external orientation from them. Based on the spare point cloud, the software creates a dense point cloud and, after that, the polygon mesh. In the next step, the mesh is covered with a texture. In the case of using 3D models created for VR, the models must be optimized (decimated) because too many polygons are undesirable. After that, we get a 3D model of an object; it always depends on how big and complicated the documented object is. If the object is complicated, there must be some additional model adjustments.

Another possibility to get a real 3D model of a historical monument or a documented object in general is the laser scanning technology. Nowadays, there are a lot of models of laser scanners that offer the creation of point clouds. But not all laser scanners are equipped with a camera for the texturing of 3D models. In some cases, it is better to use the laser scanning technology, sometimes it is better to use close - range photogrammetry. A new trend that emerged last year is to combine both technologies into one project. This possibility requires special software, such as the Capturing Reality software. After some experiments, it is appropriate to say that it depends very much on the shape and texture of the object.

\subsection{Data optimization}

Most models must be optimized after they are created (Pavelka, 2015). Only occasionally is a model usable when exported from photogrammetrical software. Above all, it is necessary to edit the created 3D model, which involves point cloud cleaning, polygon mesh decimation, repairing the texture or surface cleaning. For this reason, there are a lot of software applications (for example 3DS Max, Maya, Blender, ZBrush, etc.). In these programs, it is possible to delete some mesh parts, fill in holes or, for example, create a sculpture base. We can demonstrate mesh decimation on a part of an old vessel from Croatia (an amphora part found in the sea near Drače Village on Pelješac Peninsula). In figures 2 and 3, there are examples of mesh decimation: in figure 2 you can find a model with 100,000 polygons, while in figure 3 , there is a decimated polygon mesh with 10,000 polygons.

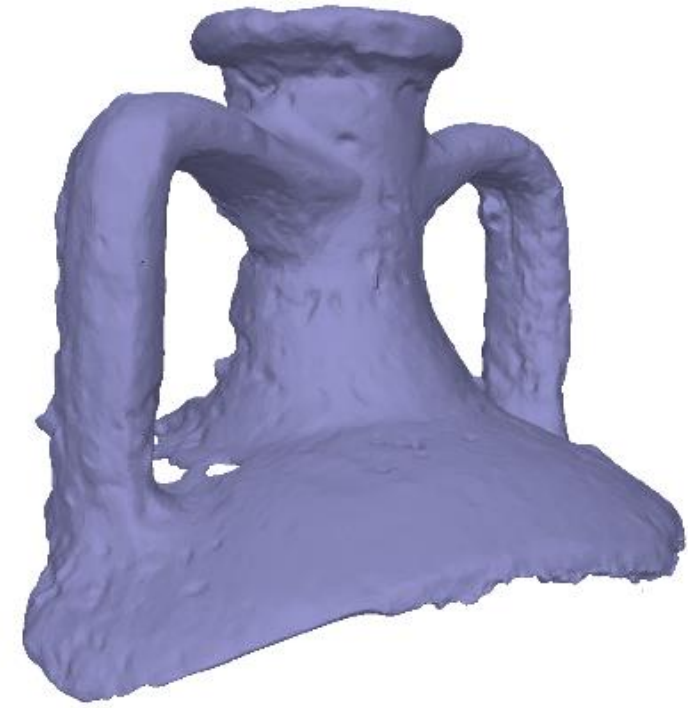

Figure 3. Mesh decimation - 100,000 polygons

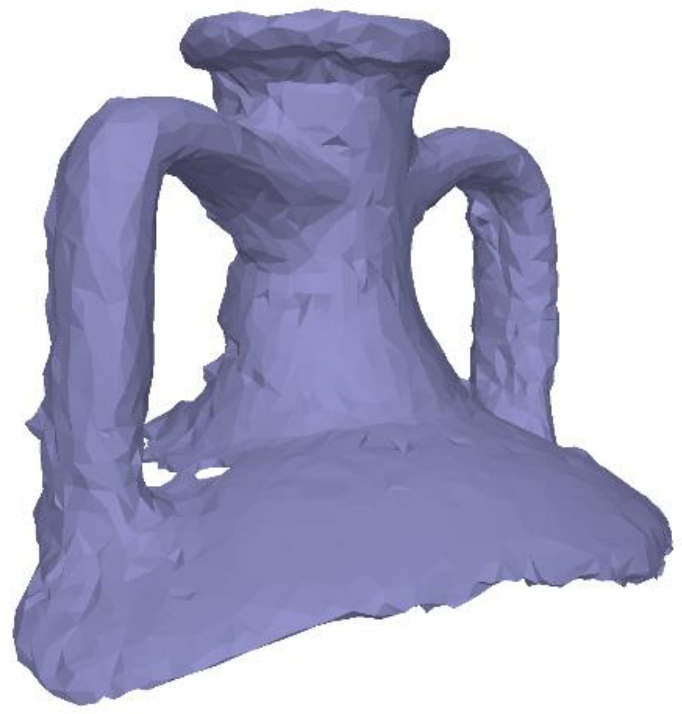

Figure 4. Mesh decimation - 10,000 polygons

In this case, it is not necessary to have a mesh with millions of polygons because after decimation a texture will be created that hides minor inequalities.

All changes and optimization always depend on the model type and the next use of the model. When we have decimated, cleaned or edited a model, it can be loaded back to the original photogrammetric software and the texture process can be started. As an example, two models were created based on two meshes (see both in figures 3 and $4-100,000$ polygon model and decimated 10,000 polygon model). In figures 5 and 6 , the results are compared against each other. 


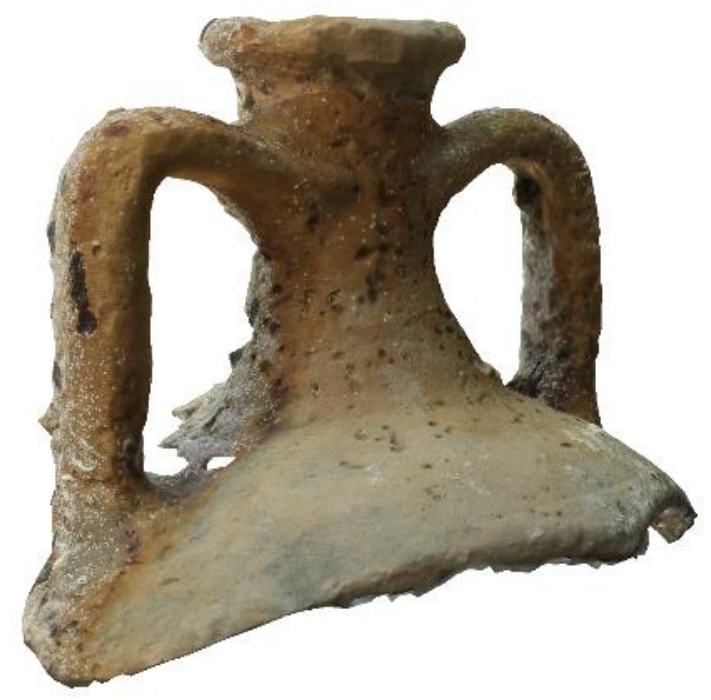

Figure 5. 10,000 model with 4k texture

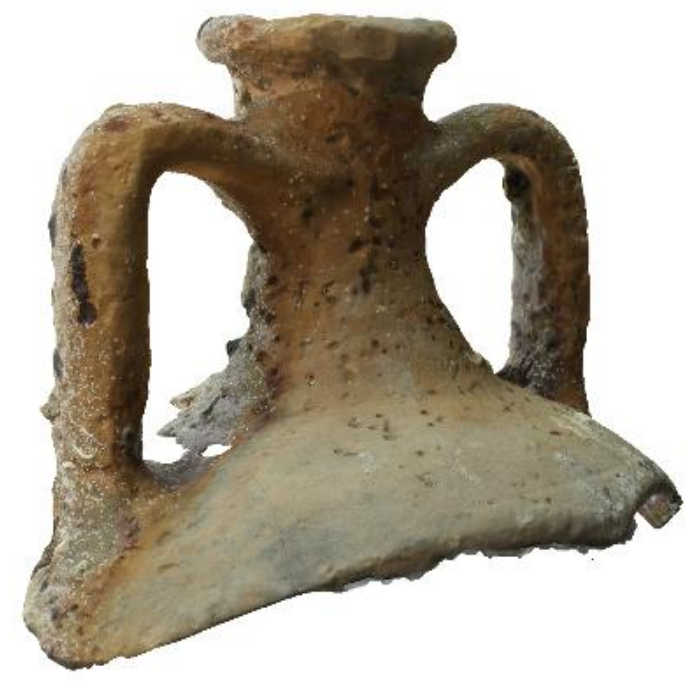

Figure 6. 100,000 model with 8k texture

As you can see in figures 4 and 5 , there is no difference between the models. Polygons are very burdensome to the game engine where models are loaded after editing, so it is necessary to reduce them. If the reduction level is well chosen, the difference is not even recognized. Other important information is the size of the model and the texture. A model with 10,000 polygons and a $4 \mathrm{k}$ texture is more than by $75 \%$ smaller. So choosing well all the parameters and setting a good balance between quality and size is very important.

\subsection{Integration to game engine}

Game engines are the best way how you can bring a model alive in VR (fig.7). There are two most popular engines, Unreal Engine and Unity. Being unable to compare which is better or worse, Unreal Engine was used for our project because it seemed more intuitive to VR control.

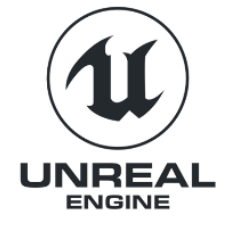

\section{$\Theta$ unity}

Figure 7. Logos of engines

As already mentioned, the model has to be adjusted. If we want to load large models that cannot be reduced due to the loss of detail, it is necessary to divide the model into several smaller models, modify these parts in the mentioned programs and upload them in parts to the game engine. It is very important not to transform the parts, not to enlarge them, increase the scale or to interfere in their position in 3D space (Faltynova, 2016). If we do so, individual parts will shift and not follow each other. For example, the complex of Nahum's shrine in Iraqi, Kurdistan is shown (fig. 8-11), which was documented using photogrammetry and laser scanning during two Czech expeditions in 2018.

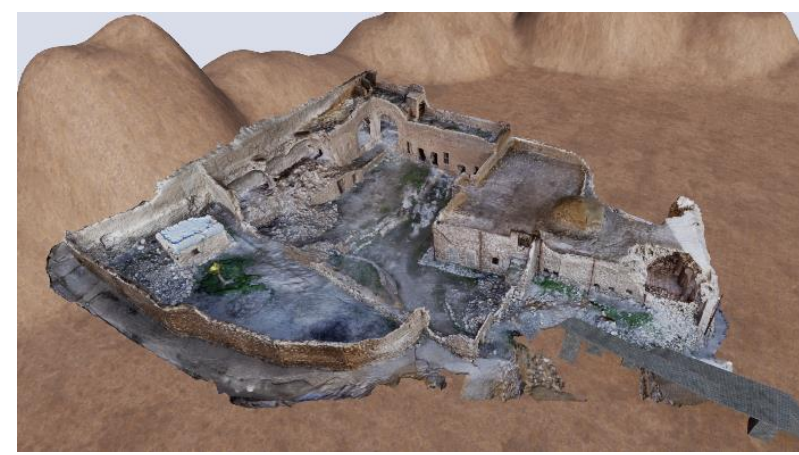

Figure 8. 3D model of Nahum's shrine created by IBMR

The model of Nahum's shrine was divided into 6 parts, the texture was calculated for each part with an $8192 \times 8192$ resolution to preserve the details inside and outside the tomb. The $8 \mathrm{k}$ resolution of the texture is the maximum that Unreal Engine can display (Pavelka, 2016).

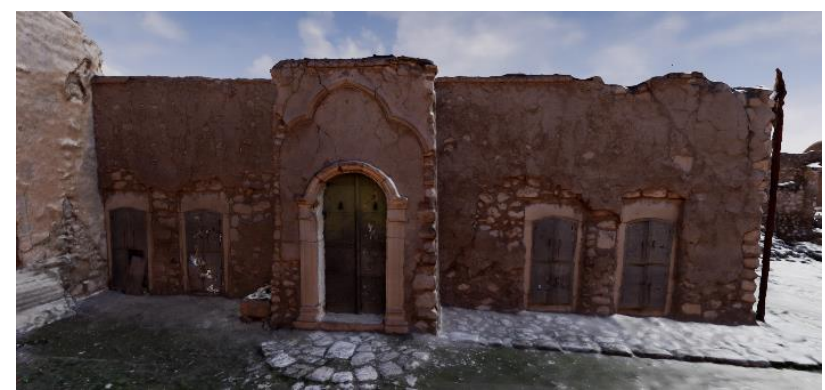

Figure 9. Texture detail - outside

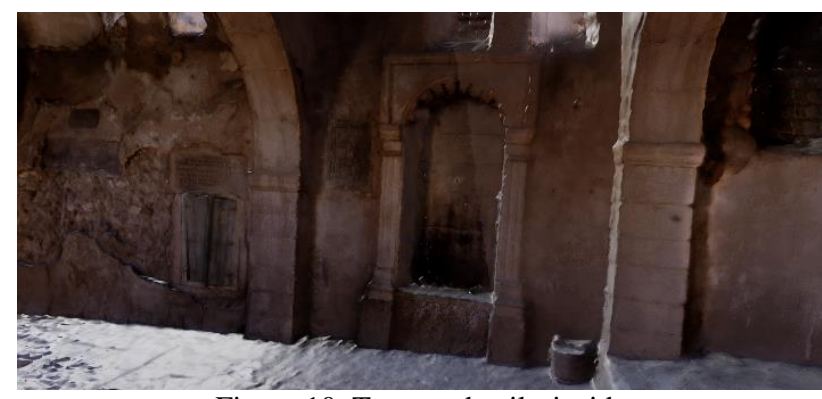

Figure 10. Texture detail - inside 


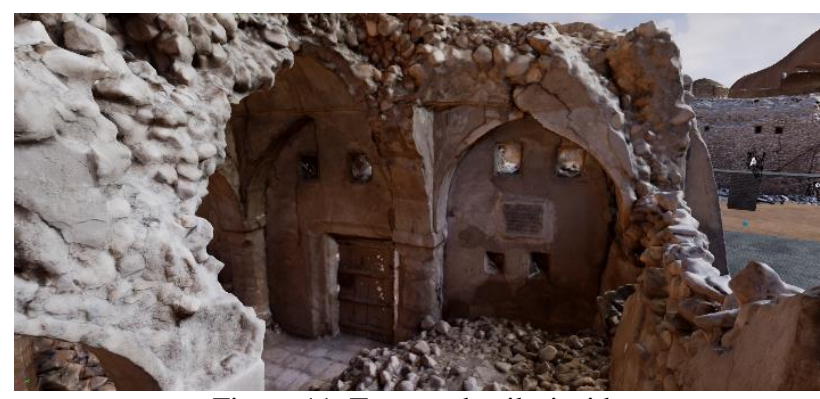

Figure 11. Texture detail - inside

If we do not split the model and use only one texture on the whole object, the texture will be blurred. Game engines allow us to build lighting, shadows, create landscape, vegetation, etc. Unreal Engine also has o a few plugins for creating real terrain using DRM or DSM (digital relief model or digital surface model).

A DSM model can be obtained with the help of drones and aerial photogrammetry or by classical geodetic methods. DRM can be made after filtering or editing DSM (a typical real relief is without vegetation, constructions, buildings and cars, for example). Our department uses all the methods for getting DRM or DSM (Sedina, 2018). Laser scanning or terrestrial photogrammetry can be used for small objects or areas, while for large areas winged drones like eBee (area up to square kilometres) or multicopters like DJI Phantom 4 or Mavic (hectares) are used. With the above mentioned methods, we can get the whole area, both 3D models of historical monuments and their surroundings by using terrestrial and aerial photogrammetry (Matouškova, 2016).

\section{VIRTUAL MUSEUM}

The idea of creating a VR museum came up about two years ago when VR technology began to expand (Miller, 1992). For VR technology, it is necessary to use special $3 \mathrm{D}$ goggles. The first breakthrough goggles that allow entry in virtual reality, Oculus rift goggles, were introduced in May 2016 (Robertson, 2019). After a short time, in June 2016, the HTC Company released HTC Vive glasses. At that time, the idea of creating a virtual museum was conceived. The Department of Geomatics at the Czech Technical University, Faculty of Civil Engineering has a number of very detailed historical models, but the possibility of their detailed modern visualization is still missing. The models were mainly created as documentation or base points for reconstruction, contouring, etc (Matouskova, 2016). But now, the models come to life in a virtual world, where they find their extended use. Suddenly, you can visit Nahum's shrine, see the reconstructions of historic vessels, explore and analyse historical sculptures in detail and there is no need to go anywhere.

The main benefit of VR for our department is the fact that we can go to a research site only once and carry out all further analysis including browsing, measuring, reconstructing and visualization in the virtual world in the laboratory.

The virtual museum was created in SketchUp and uploaded to Unreal Engine; inside the museum, there are four rooms (sections) and a corridor which connects them. Every room is focused on different models. Currently, the museum has around 12 models and 3 of 4 sections have been opened, but the collection is getting larger every month. In all sections, information about the model and photographs is displayed on the wall (fig.12-19).

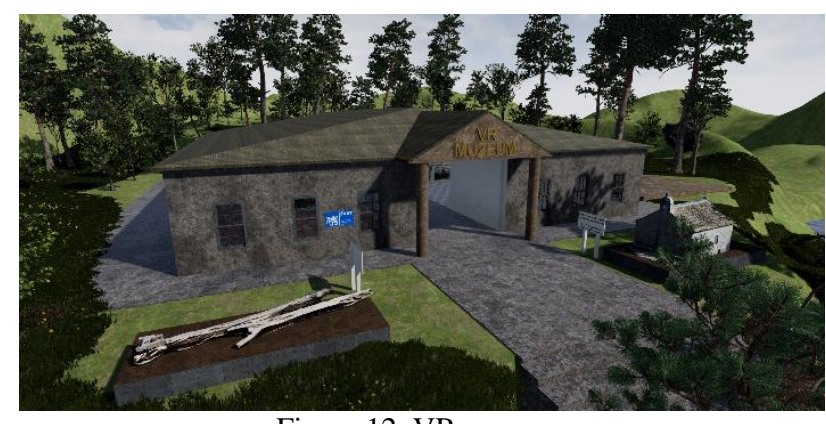

Figure 12. VR museum

\subsection{Section 1 - Iraq section}

In this section, there are objects from Iraq. As a major object, the scaled-down Nahum's shrine is located here. It is passable, thus you can pass through to look at the shrine parts. There is also a detailed column, a decorated niche and an ancient vessel, for example.

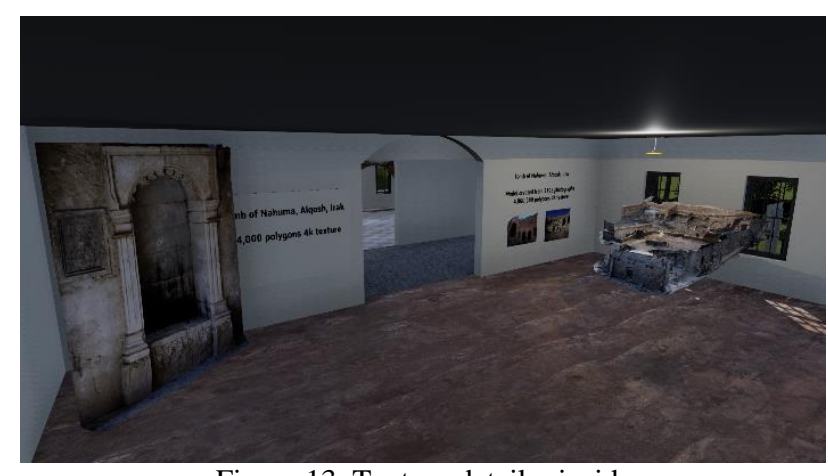

Figure 13. Texture detail - inside

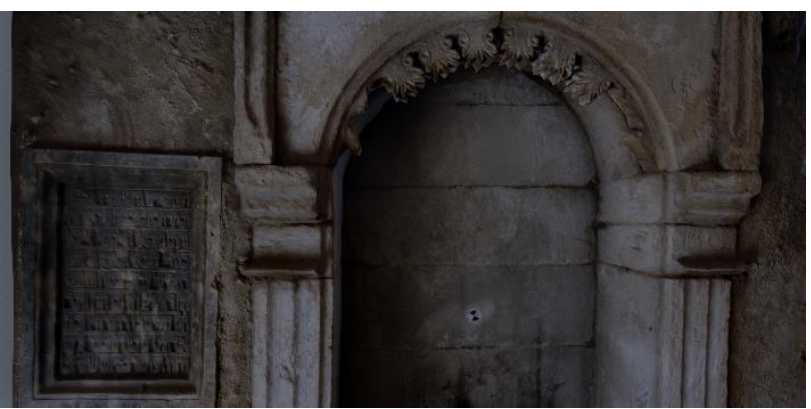

Figure 14. Texture detail - inside

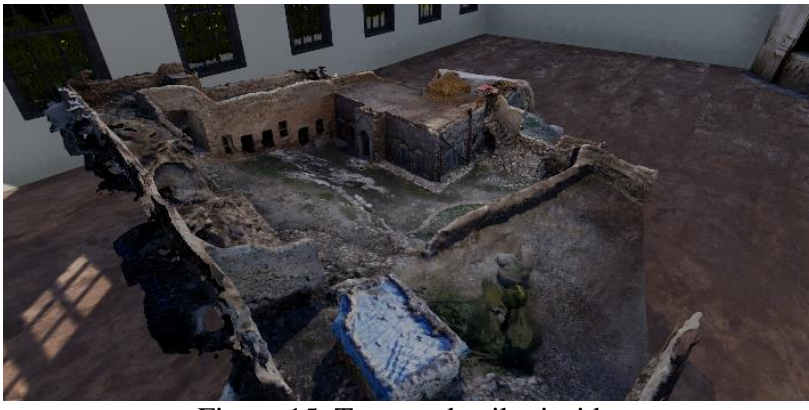

Figure 15. Texture detail - inside

\subsection{Section 2}

In section 2, there is a model of St. Wenceslas monument from Wenceslas Square in Prague. This model was created to analyze the state of all sculptures and to keep it up to date. Another model is a medieval castle ruin from Stafford in England. This scaled- 
down model is able to be grabbed and you can rotate it in your hand to discover all parts of the ruin. The third model is an arch from Rethymnon's fortress in Crete / Greece from the 16th century (Explorecrete web, 2019).

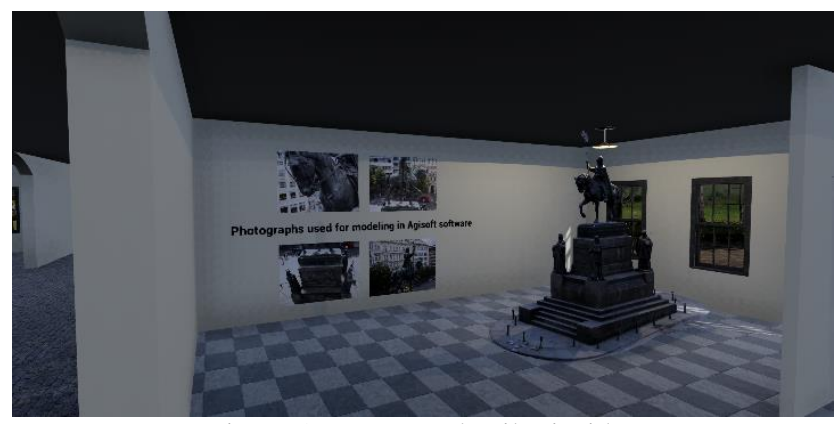

Figure 16. Texture detail - inside

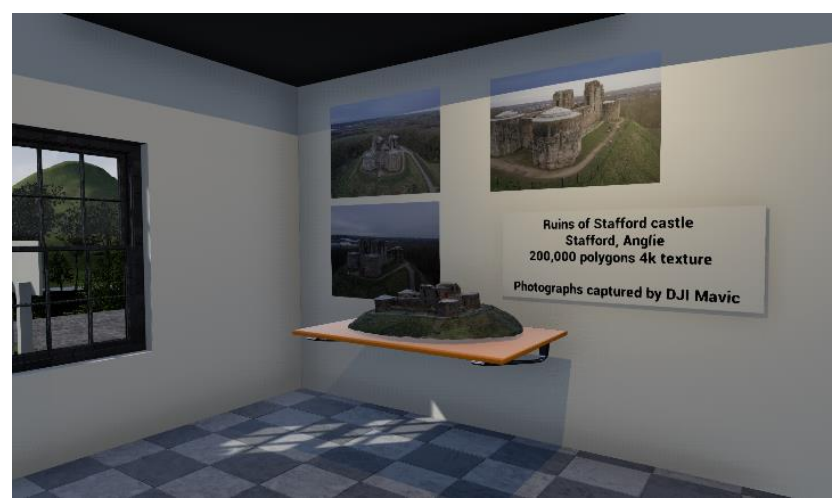

Figure 17. Texture detail - inside

\subsection{Section 3}

There is a table with more than 8 historical shards from different archaeological sites (fig. 18).

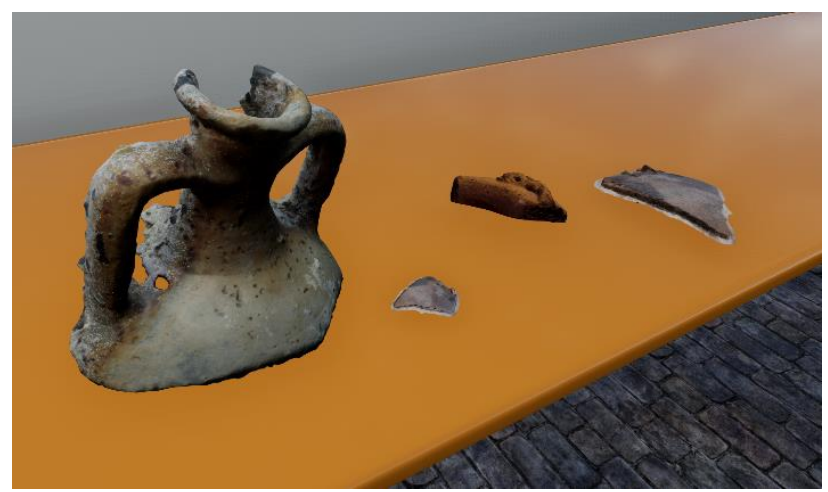

Figure 18. Texture detail - inside

\subsection{Section 4}

The fourth and latest section is dedicated to aerial photogrammetry and cartography; it contains landscape models including DSM. In figure 18, there is a 3D model of the "Vlči jámy canyon", which is the remainder of tin mining from the Medieval Period in the Ore Mountains / Czech Republic. The canyon is the remnant of a sunken underground space from the mining period.

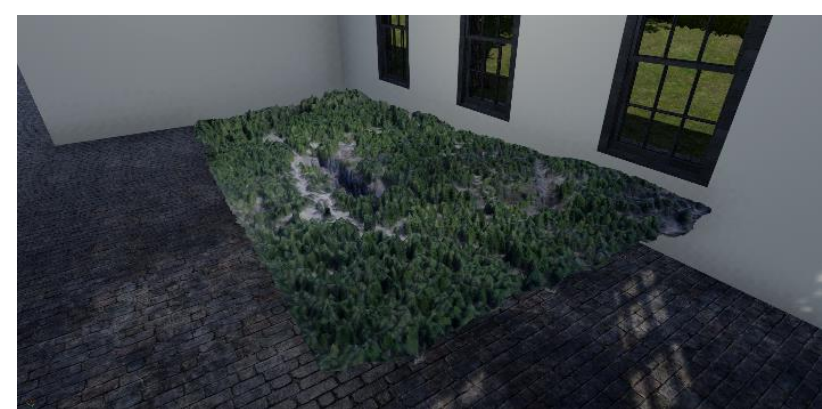

Figure 19. Textured model - "Vlčí jámy" - landscape and mining monument

\section{CONCLUSION}

Virtual Reality is currently a very popular and modern technology. For photogrammetry or laser scanning in cultural heritage documentation, this is a great benefit in terms of modern and active visualization. Thanks to VR and photogrammetry, we can get perfect replicas of real objects. In VR, objects remain intact, there is no need to fix them, no need to worry about them, they will remain available to us as a visualization of their appearance at the time of data acquisition. The development of VR will surely continue and so it is very important to start using it already in its beginnings. The first goals, which were set for the use of VR, together with photogrammetry and laser scanning also for heritage documentation, were successfully reached. Nowadays, from our point of view and with contemporary technology, the best workflow could be found. The Virtual Museum contains several historical optimized models that allow visitors to explore them in detail. In the future, we would like to add more sections as needed, the museum is ready for its possible extension. There are no limits, maybe, only the disk capacity and the level of detail.

\section{ACKNOWLEDGEMENTS}

This research was partially supported by a student's Internal grant of the Czech Technical University Nr. SGS19/048/OHK1/1T/11.

\section{REFERENCES}

Explorecrete.com, 2019. Rethymnon's fortress in Crete / Greece, http://www.explorecrete.com/crete-

west/Rethymnon_Fortezza.html (Retrieved 15 ${ }^{\text {th }}$ June 2019).

Falynova, M., Raeva, P., Poloprutsky, Z., Matouskova, E. and Housarova, E., 2016. Complex analysis and documentation of historical buildings using new geomatics methods. The Civil Engineering Journal, 2016-4(27). https://doi.org/10.14311/CEJ.2016.04.0027

Matousková, E., Starkova, L., Pavelka, K., Novacek, K., Sedina, J., Faltynová, M., Housarová, E., 2016. Using remotely sensed data for documentation of archaeological sites in northeaster Mesopotamia. ISPRS - International Archives of the Photogrammetry, Remote Sensing and Spatial Information Sciences, Vol. XLI-B5, pp.335-342.

https://doi.org/10.5194/isprsarchives-xli-b5-335-2016 
Miller, G., Hoffert, E., Chen, S., Patterson, E., Blackketter, D., Rubin, S., Applin, S., Yim, D., Hanan, J., 1992. The virtual museum: Interactive 3D navigation of a multimedia database. The Journal of Visualization and Computer Animation, Vol. 3(3), pp.183-197.

https://doi.org/10.1002/vis.4340030305

Pavelka, K., Sedina, J., Housarova, E., Martan, M., 2016. Using multi image photogrammetry for precise documentation of historical building parts. 16th International Multidisciplinary Scientific GeoConference SGEM 2016, Informatics, Geoinformatics and Remote Sensing. Vol. 2, pp. 1083-1090. https://doi.org/10.5593/SGEM2016/B22/S10.138

Pavelka, K., Faltynova, M., Matouskova, E., Sedina, J., 2015. Documentation, 3D modelling and replication of archaeological artefacts. 15th International Multidisciplinary Scientific GeoConference SGEM 2015, Informatics, Geoinformatics and remote sensing. Vol. 1, pp. 109-116. https://doi.org/10.5593/SGEM2015/B21/S7.015

Sedina, J., Housarova, E., Raeva, P., 2017. Using of RPAS in precision agriculture. 17th International Multidisciplinary Scientific GeoConference SGEM 2017, Informatics, Geoinformatics and Remote Sensing. Vol. 17, pp. 331-338. https://doi.org/10.5593/sgem2017/23/S10.041

Sedina, J., Pavelka, K., Reznicek, J., Matouskova, E. and Faltynova, M., 2015. Combining laser scanning and IBM technology in Cultural heritage. 15th International Multidisciplinary Scientific GeoConference SGEM 2015, Informatics, Geomatics and remote sensing. Vol. 1, pp. 61-68. https://doi.org/10.5593/SGEM2015/B21/S7.009

Sedina, J., Housarova, E., Raeva, P., 2018. Using RPAS for the detection of archaeological objects using multispectral and thermal imaging. European Journal of Remote Sensing, Vol. 52(sup1), pp.182 -191

https://doi.org/10.1080/22797254.2018.1562848

Robertson, A., 2019. The Oculus Quest and Oculus Rift S launch on May 21st, and pre-orders open today. https://www.theverge.com/2019/4/30/18524055/oculus-questrift-s-vr-headset-launch-date-preorders-price (Retrieved $15^{\text {th }}$ June 2019).

Williams, R., 2016. HTC Vive pre-orders to start on February 29, The Telegraph. https://www.telegraph.co.uk/technology/news/12092607/HTCVive-pre-orders-to-start-on-February-29.html (Retrieved 28th January 2019). 